\title{
Erratum to: Infestation Rates and Tiller Morphology Effects by the Switchgrass Moth on Six Cultivars of Switchgrass
}

\author{
Veronica Calles Torrez • Paul J. Johnson • Arvid Boe
}

Published online: 22 March 2013

(C) Springer Science+Business Media New York 2013

Erratum to: Bioenerg Res

DOI 10.1007/s12155-013-9306-7

In Table 3, of the original version, the column headings were incorrect. The correct version is shown here.

Table 3 Weights of healthy tillers and tillers infested by the larva of the switchgrass moth at Brookings, SD, USA

\begin{tabular}{|c|c|c|}
\hline \multirow[t]{2}{*}{ Tiller type } & \multicolumn{2}{|l|}{ Year } \\
\hline & 2011 & 2012 \\
\hline & \multicolumn{2}{|c|}{$\left(\mathrm{mg}\right.$ tiller $\left.{ }^{-1}\right)$} \\
\hline Healthy & $607^{\mathrm{a}}$ & $657^{\mathrm{a}}$ \\
\hline Infested & 206 & 185 \\
\hline
\end{tabular}

$\overline{{ }^{a} \text { Comparison of healthy and infested tiller significant at } 0.01 \text { level }}$ by $t$ test

The online version of the original article can be found at http://dx.doi.org/ 10.1007/s12155-013-9306-7.

\footnotetext{
V. Calles Torrez $\cdot$ P. J. Johnson $(\bowtie)$

Insect Biodiversity Lab, Department of Plant Science, South Dakota State University, Brookings, SD, Box 2207A, 57007, USA

e-mail: paul.johnson@sdstate.edu

V. Calles Torrez

e-mail: veronica.callestorrez@sdstate.edu
A. Boe
Department of Plant Science, South Dakota State University,
Brookings, SD, Box 2140C, 57007, USA

e-mail: arvid.boe@sdstate.edu 